\title{
Enhancement of DC electrical Conductivity and Creep Relaxation for PVA Samples Doped with $\mathrm{SrCl}_{2}$
}

\author{
A. B. Elaydy ${ }^{1}$ and F. A. Akraiam ${ }^{2}$ \\ 1) Physics Department-Faculty of Science-Suez Canal University, \\ Ismailia, Egypt \\ 2) Physics Department-Faculty of Science-Omar Al-Mukhtar University, \\ Elbieda, Libya
}

A matrix composed of polyvinyl-alcohol; (PVA) mixed with different concentration ratios of granular strontium chloride $\left(\mathrm{SrCl}_{2} \cdot 6 \mathrm{H}_{2} \mathrm{O}\right)$ were prepared by casting technique method at room temperature. I-V characteristcs and hence $d c$ electrical conductivity values, as well as mechanical characteristcs such as, Young's modulus, creep relaxation, and energy stored properties for these samples were determined.

\section{Introduction:}

Electronic transport in conjugated polymers (CPs) has become an increasingly intersting area of research, partly because of the unique electronic properties of CPs and partly because these materials possess great potential for device application, such as Schottky junctions, batteries, displays, sensors, and microelectronics [1-5]. These applications are hampered by the poor mechanical properties of these conducting polymers. Therefore, much attention has been paid to synthesizing various composite materials in which conducting polymers are embedded in some insulating polymer matrices with higher mechanical properties [6-9].

Attention has been focused on polyvinyl alcohol (PVA) for more than 50 years because of its unique chemical and physical properties as well as its industrial applications[10]. Also, the possibility of replacing the metals of semiconductor inorganic materials with recently discovered conducting polymer has led to intensive interset in such materials $[11,12]$ In the present work, a thorough characterization of the electrical conductivity of $\mathrm{PVA} / \mathrm{SrCl}_{2}$ samples was measured at room temperature. Mechanical properties were also measured using local made instruments. 


\section{Experimental:}

\subsection{Samples preparation}

A matrix composed of polyvinyl-alcohol; (PVA) mixed with granular strontium chloride $\left(\mathrm{SrCl}_{2} \cdot 6 \mathrm{H}_{2} \mathrm{O}\right)$ with different ratios are given in Table (1). The pre-weighed PVA powder of molecular weight 72000 was well dissolved in bidistilled water and different additives of $\mathrm{SrCl}_{2}$. These mixtures; are placed and dried in Pittery dishes at room temperatures for several days in small closed chamber till it becomes solid thick sheets of $1.5 \mathrm{~mm}$ such technique is known as casting technique. This technique is the process of filling open molds with these mixtures. All the products of this mixture were found to be very stable, colourless, odorless and not transparent especially for low $\mathrm{SrCl}_{2}$ concentrations. Only samples with very high quality from these matrices were selected and used for both the electrical conductivity and for the mechanical measurements. The selected films were divided into six groups which are denoted it by the symbols Sr1, Sr3, Sr5, Sr7, Sr9 and Sr11 as shown in the Table (1).

Table (1): Polyvinyl-alcohol; (PVA) mixed with granular strontium chloride $\left(\mathrm{SrCl}_{2} \cdot 6 \mathrm{H}_{2} \mathrm{O}\right)$ with different concentration ratios.

\begin{tabular}{|c|c|c|}
\hline Material & Sample Code & Ratio (wt \%) \\
\hline $\mathrm{PVA} / \mathrm{SrCl}_{2}$ & $\mathrm{Sr} 1$ & $95: 5$ \\
\hline $\mathrm{PVA} / \mathrm{SrCl}_{2}$ & $\mathrm{Sr} 3$ & $85: 15$ \\
\hline $\mathrm{PVA} / \mathrm{SrCl}_{2}$ & $\mathrm{Sr} 5$ & $75: 25$ \\
\hline $\mathrm{PVA} / \mathrm{SrCl}_{2}$ & $\mathrm{Sr} 7$ & $65: 35$ \\
\hline $\mathrm{PVA} / \mathrm{SrCl}_{2}$ & $\mathrm{Sr} 9$ & $55: 45$ \\
\hline $\mathrm{PVA} / \mathrm{SrCl}_{2}$ & $\mathrm{Sr} 11$ & $45: 55$ \\
\hline
\end{tabular}

\subsection{Electrical Measurements}

Samples of polyvinyl-alcohol; (PVA) mixed with granular strontium chloride $\left(\mathrm{SrCl}_{2} \cdot 6 \mathrm{H}_{2} \mathrm{O}\right)$ with different concentration ratios; were cut from the original sheets into disk shapes with diameters $1 \mathrm{~cm}$. The disks were coated very well by gold paint to confirm good electrical contact between the two electrodes of the sample holder. A cell consists of two stainless steel cylinders of lengths 10 and $6 \mathrm{~cm}$, two copper disks in their shape as a top and a bottom bases is used for the electrical measurements, also many bulk rubber parts with different dimensions are used for insulating purposes. Very fine copper wires were well cemented on both surfaces of the sample holder. The cell including sample is put on a flat table at room temperatures. A circuit is settled in Omar Almukhtar University (Libya); and the related parameters, such as dc conductivity, capacitances were calculated using a computer program. The total dc electrical conductivity was determined by using the following equation: 


$$
\sigma=\frac{1}{R} \frac{t}{A} \quad .
$$

where: $\sigma$ is the total dc electrical conductivity; $\mathrm{R}$ is samples resistance in ohms; $\mathrm{t}$ is samples thickness in meters; A is samples cross-section area in square meters.

\subsection{Mechanical Measurements}

The stress-strain and hence Young's modulus in addition to the creep curves are important graphical measurement for mechanical properties [13]. Young's modulus in general is consider as a measure of the resistance of a solid to the change in its length when a force is applied perpendicular to its face [14]. However, they are not without some subtlety, especially in the case of ductile materials that can undergo substantial geometrical change during testing. Several topics elsewhere will appear with more detail in many modules [15]. So, the stress-strain behavior of solid polymers in general can be categorized into three common classes of the following behaviour [16]:

1) Brittle Fracture- characterized by no yield point, a region of Hooke behavior.

2) Yield Behavior- characterized by a maximum in the stress-strain curve followed by yielding deformation, which is usually associated with crazing, or shear bending.

3) Rubber-Like Behavior- characterized by the absence of a yield point maximum but exhibiting a plateau in an engineering stress-strain curve.

The stress and strain are denoted $\sigma$ and $\varepsilon$ in this module, respectively. They are determined from the used load and the measuring of the deflection from the original sample parameters. At; low strain; the curve obeys Hooke's law at low stress to and reasonable approximation, the stress is proportional to strain with the constant of proportionality of elasticity or Young's modulus. As strain is increased, many polymeric materials eventually deviate from this linear proportionality, the point of departure being termed the proportional limit. This nonlinearity is usually associated with stress-induced "plastic" flow in the specimens.

Another mechanical property is the creep, in which the plastic strain is dependent not only on the stress but also on time, was also studied. Creep tests were carried out by loading samples by suitable constant mass and observing the development of strain as a function of time at room temperature. Then the measured strain $(\varepsilon)$ was plotted against time $(\mathrm{t})$ in seconds. Also the different calculated area's under stress-strain curves up to a given value of strain is the total mechanical energy per unit volume consumed by the material in straining it to that value; $\mathrm{U}$. Also the half area values under F- $\Delta \mathrm{L}$ curve for the portion of Hookes law is obeyed was easily determined shown as the following equation [17]: 


$$
\mathrm{U}=0.5(\mathrm{~F} \times \Delta \mathrm{L}) \mathrm{J}
$$

where $\mathrm{F}$ is the applied load, and $\Delta \mathrm{L}$ is sample strain. When molecular slip and other mechanisms for energy dissipation are absent, this mechanical energy is stored reversibly within the different specimens as strain energy. When the stresses are low enough the specimens remain in the elastic range, and the strain energy is just the triangular area in force-elongation change.

Stress-strain data were determined at room temperature using locally tester [18]. The samples for mechanical measurements were cut from the original films into bar shapes with length $3 \mathrm{~cm}$. A sensitive traveling microscope with accuracy $\pm 0.01 \mathrm{~mm}$ was used to detect any small variations in the length of the test specimens for stress-strain and creep relations. The different specimens were will clamped from one end and loaded from the other free end. Different loads were used for the different specimens to give $4.9 \mathrm{Mpa}$ as a constant stress value.

\section{Results:}

\subsection{Electrical conductivity}

The measurements of the dc conductivity, $\sigma_{\mathrm{dc}}$; at room temperature were calculated from current-voltage relationships as we mentioned above and the result was shown in Fig. (1). Fig. (2) shows the relationships between the dc electric conductivity values and $\mathrm{SrCl}_{2} \mathrm{wt} \%$ and from it we note that the conductivity were reached a maximum value of $1.02 \times 10^{-4}(\Omega \mathrm{m})^{-1}$ for a sample Sr5 which contains $25 \% \mathrm{SrCl}_{2}$; and by increasing of strontium chloride content the conductivity decreasing again for all samples. Fig. (3) shows also the capacitance of the different samples as function in $\mathrm{SrCl}_{2}$ concentration.

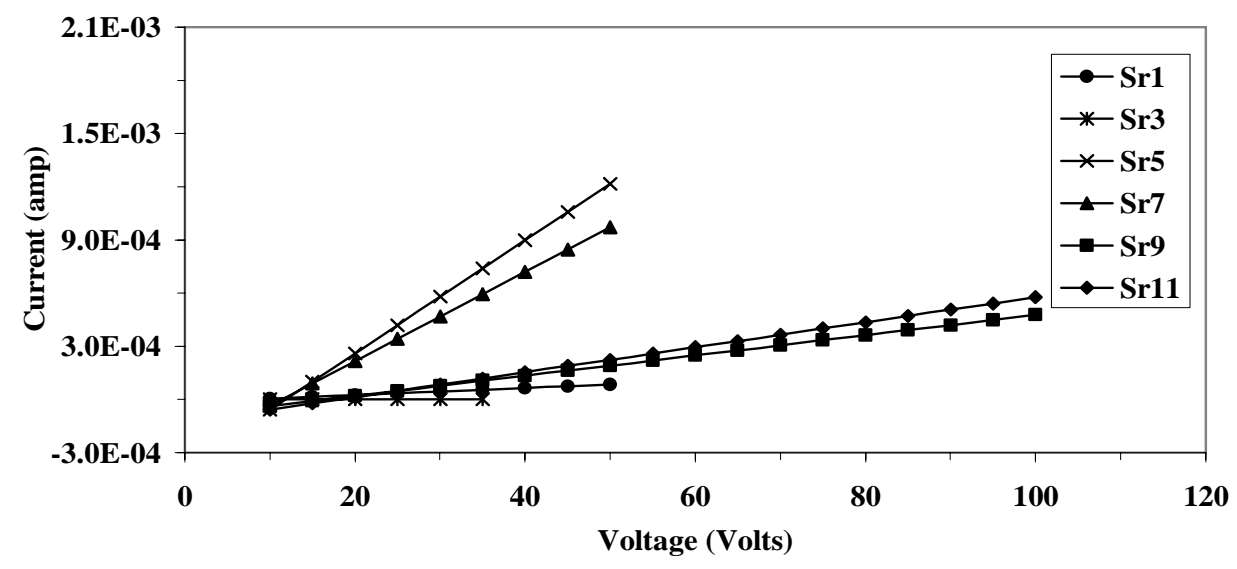

Fig. (1): IV-Characteristics for all $\mathrm{PVA} / \mathrm{SrC1} 2$ samples at room temperature. 


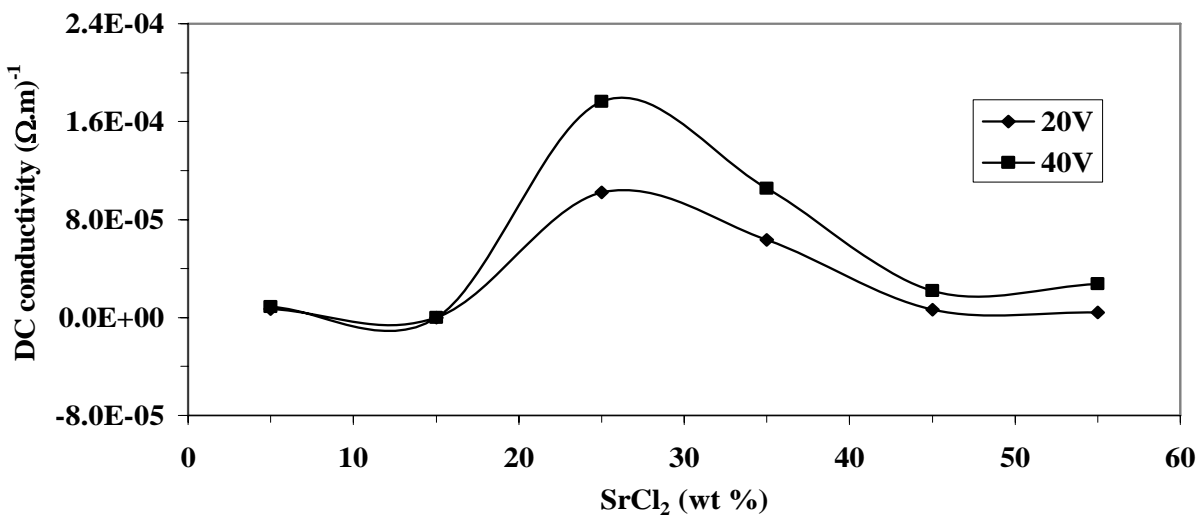

Fig. (2): DC conductivity as a function in $\mathrm{Srcl}_{2}$ content (wt\%) in $\mathrm{SrCl}_{2} / \mathrm{PVA}$ samples.

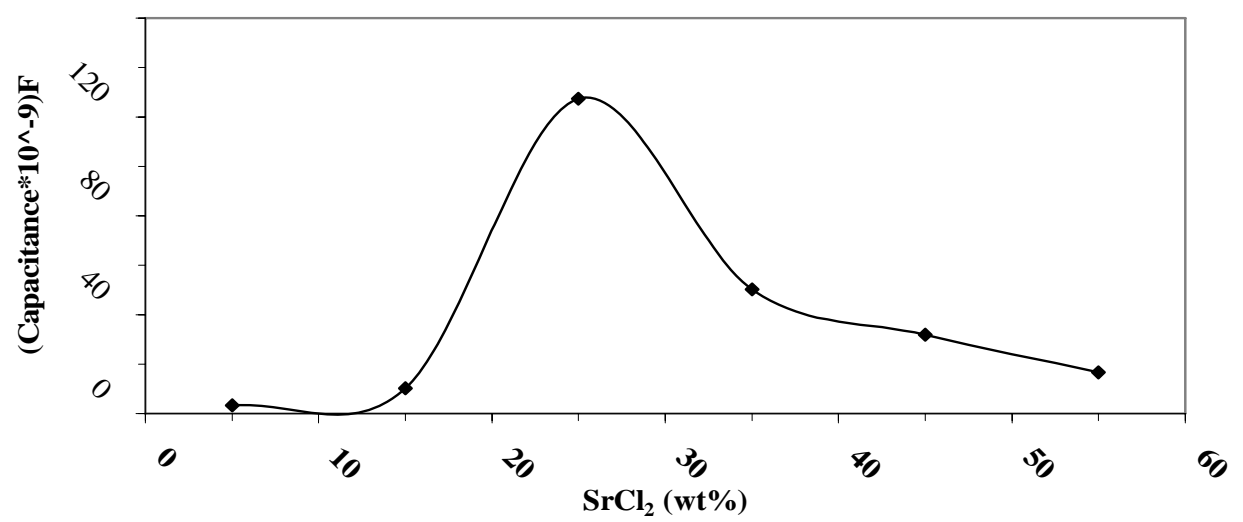

Fig. (3): the capacitances of the samples as function in $\mathrm{SrCl}_{2}$ concentration in $\mathrm{PVA} / \mathrm{SrCl}_{2}$ Samples.

\subsection{Young's modulus and creep relations}

Our experiment for stress-strain of different samples; were run at room temperature to avoid the transformation by the heat resulting from the access loads. Also, because the real materials always yield to some extent under the influence of the applied forces, we shall develop an apparatus which directly give the relation between tensile strain and tensile stress. Stress-strain curves are shown in Fig. (4). From the figure Young's modulus (stretch modulus) values of all samples were calculated by using the Eqn. (2) above. Also, Fig. (5) shows Young,s modulus values as function of $\mathrm{SrCl}_{2}$ contents in $\mathrm{PVA} / \mathrm{SrCl}_{2}$ specimens. Fig. (6) shows the energy of these samples as functions of their length elongation. Also; other several runs were conducting in order to choose the most suitable conditions of the creep experiments. Creep curves at 5.9 and 2.9 Mpa as constant loads and at room temperatures for the different samples which 
are presented in Figs $(7,8)$. From curves we note that the sample Sr3 which contains $15 \mathrm{wt} \% \mathrm{SrCl}_{2}$ has the most higher strain. This may be explained, by increasing the elastisity values by increasing with further increase of $\mathrm{SrCl}_{2}$ content. This behaviour is also obtained recoreded in Fig. (9), through the dependence of instantaneous strain $\varepsilon_{0}$ on the $\mathrm{SrCl}_{2}$ concentration at $\sigma=5.9 \mathrm{MPa}$.

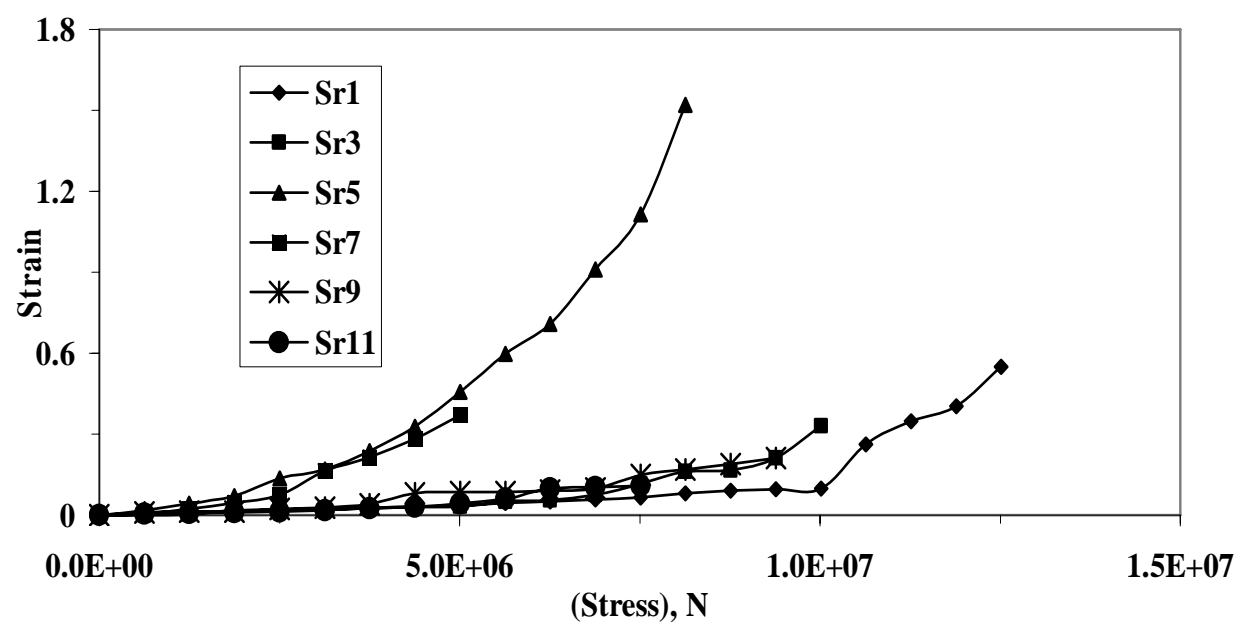

Fig. (4): Stress-Strain relationship for $\mathrm{PVA} / \mathrm{SrCl}_{2}$ samples with different concentrations wt\%.

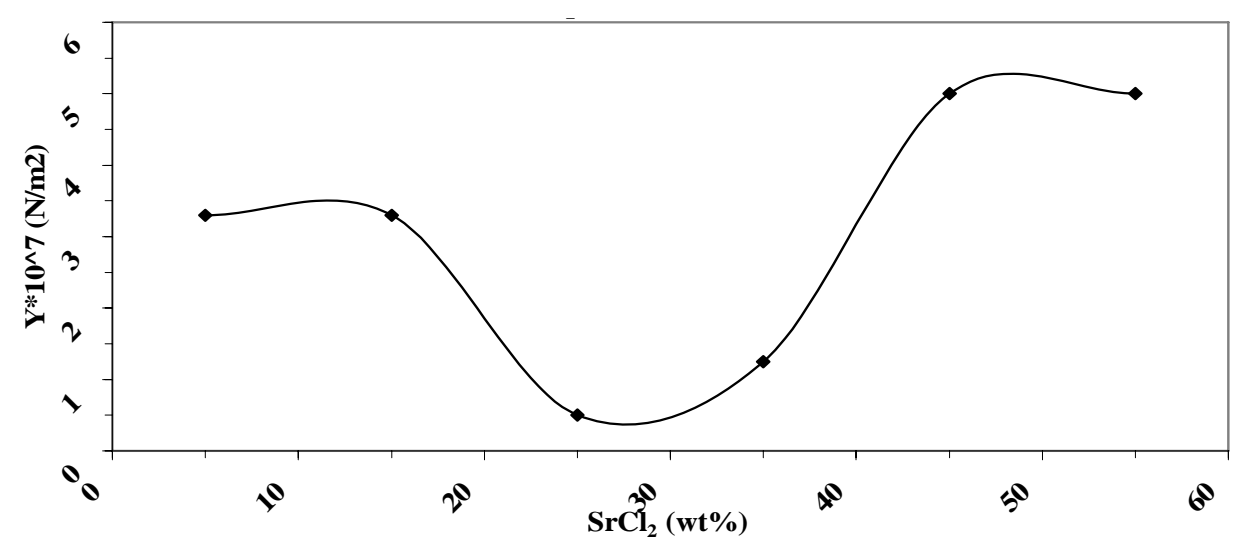

Fig. (5): Young,s modulus as function in $\mathrm{SrCl}_{2}$ contents in $\mathrm{PVA} / \mathrm{SrCl}_{2}$ specimens. 


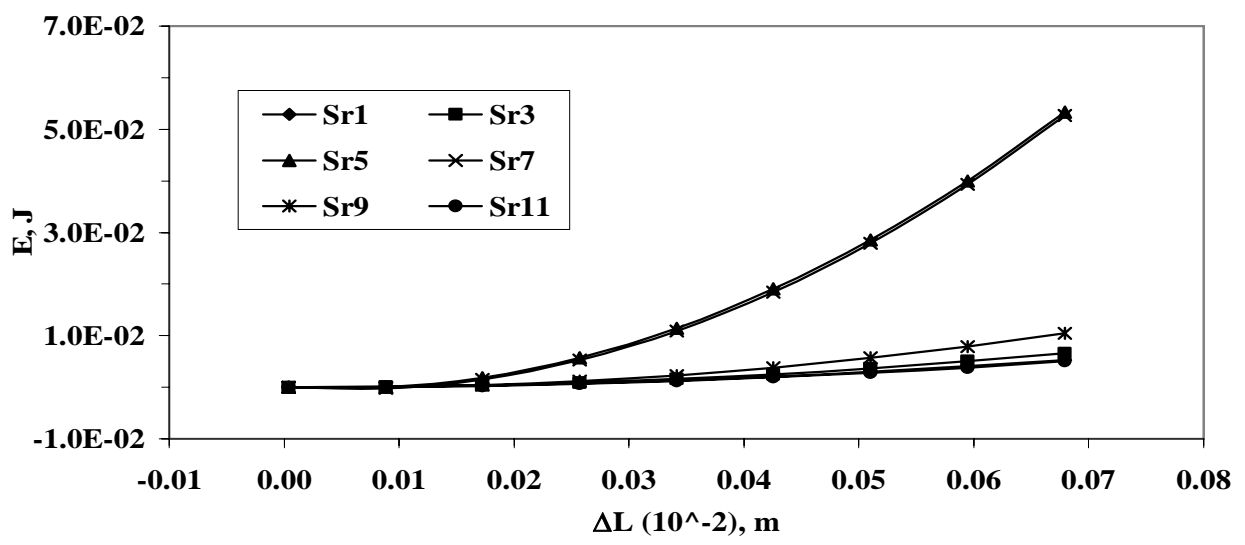

Fig. (6): Energy as a function in specimen length elongation.

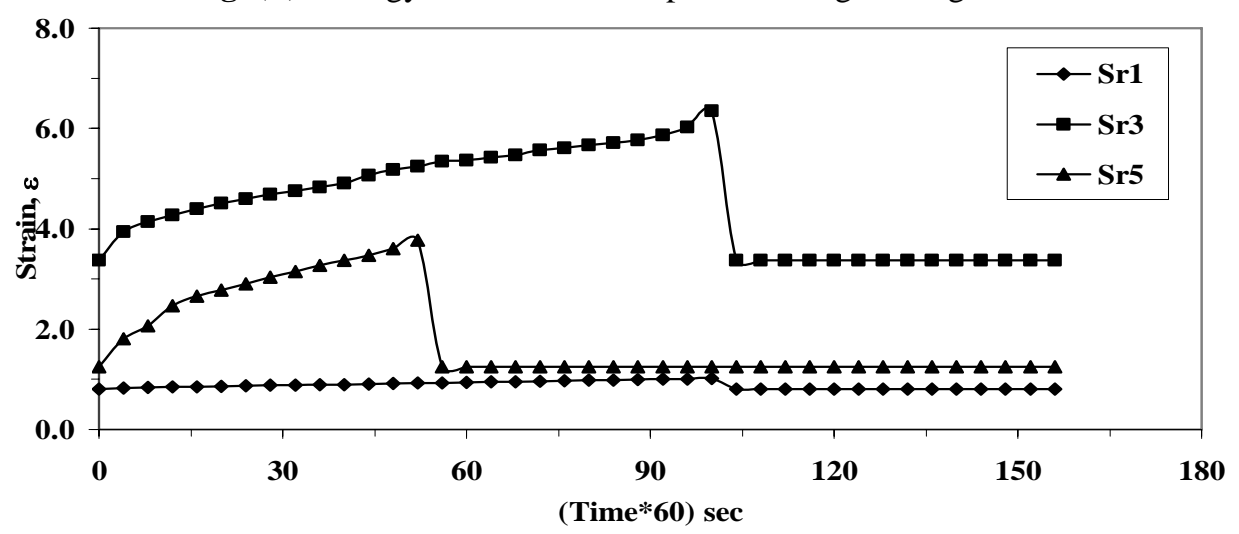

Fig. (7): The forward and backward creep relations for Sr1, Sr3, and Sr5 Specimens at 5.9 Mpa as a constant stress.

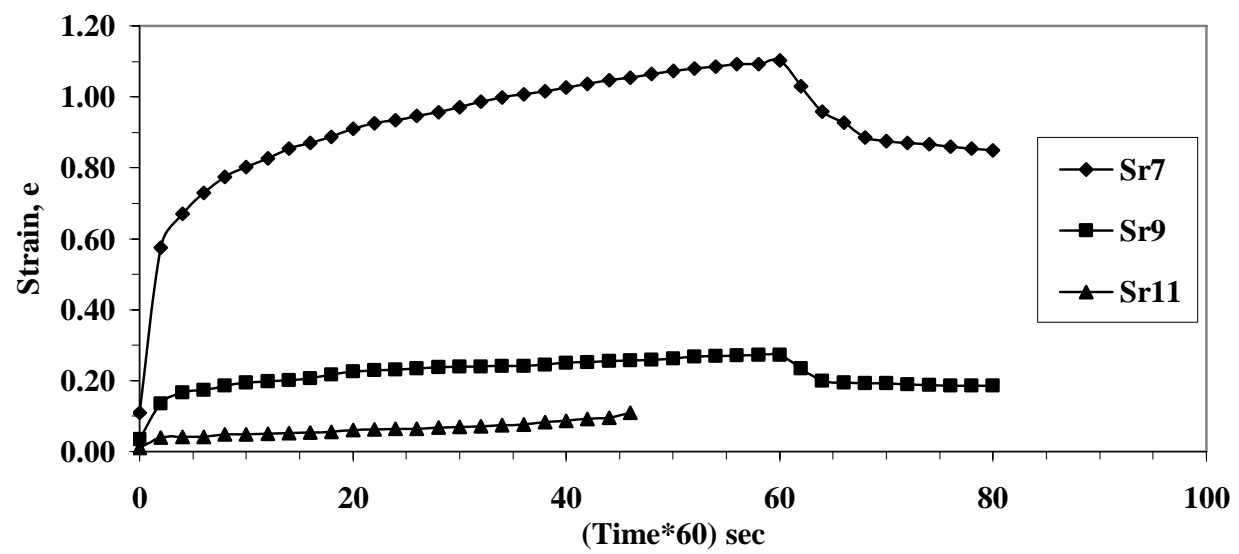

Fig. (8): The forward and backward creep relations for Sr7, Sr9, and Sr11 Specimens at 5.9 Mpa as a constant stress. 


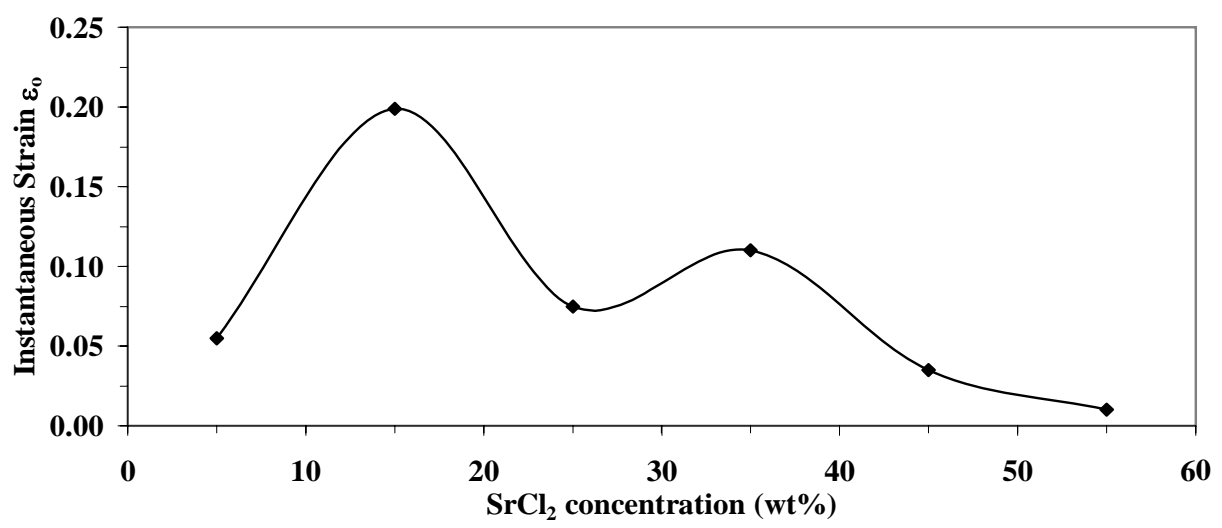

Fig. (9): The variation of instantaneous strain with concentrations of $\mathrm{SrCl}_{2}$ at $\alpha=5.9$ Mpa.

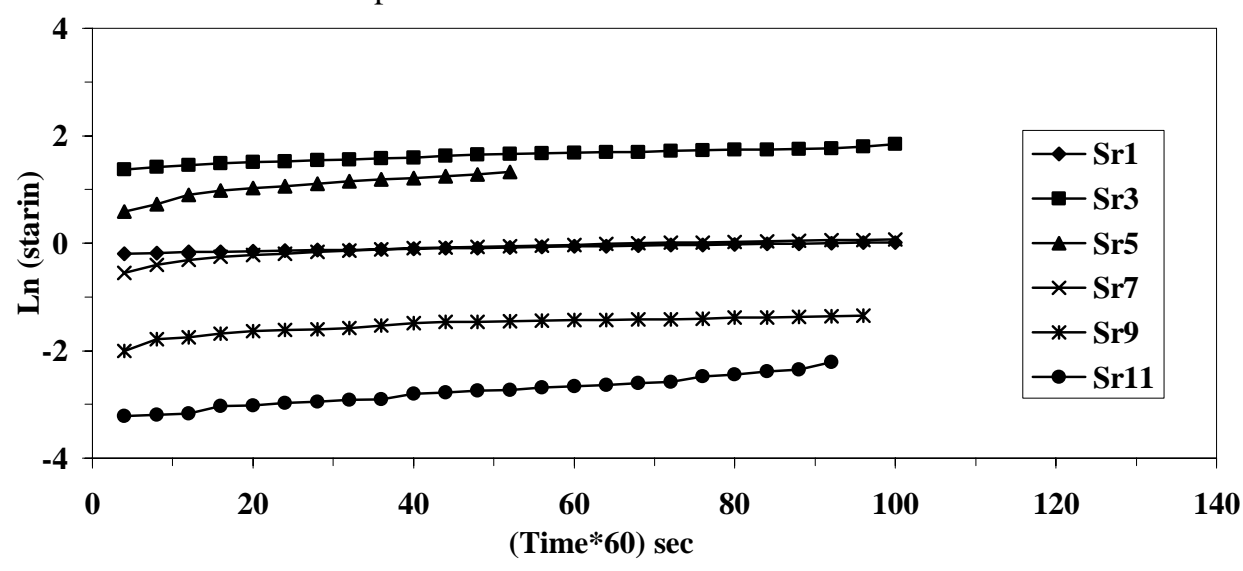

Fig. (10): The elastic strain as a function in time at room temperature at $\alpha=5.9$ Mpa.

\section{Conclusions:}

The values of dc conductivity, $\sigma_{\mathrm{dc}}$, at room temperature were calculated from current-voltage relationships. The relationship between the dc electric conductivity values and $\mathrm{SrCl}_{2}$ contents showed maximum value of $1.02 \times 10^{-4}$ $(\Omega \mathrm{m})^{-1}$ for a sample $\mathrm{Sr} 5$, which contains $25 \% \mathrm{SrCl}_{2}$; and further increasing of strontium chloride content cause decrease in the electrical conductivity. From the relationships between the capacitance as function of $\mathrm{SrCl}_{2}$ concentration, we note that the capacitance increasing with increasing $\mathrm{SrCl}_{2}$ content may be due to the increase in the mobility of the charge carriers at higher concentration but after attaining a maximum value the capacitance decreases with further increase of $\mathrm{SrCl}_{2}$ concentration. The stress-strain and creep curves and the total mechanical energy per unit volume consumed by the samples are considered the main parameters of a material's mechanical properties. 


\section{References:}

1. Handbook of Conducting Polymers; Skotheim, T. A., Dokker: New York, (1986).

2. S. Stafsform, J. L. Bredas, A. J. Epstein, H. S. Hoo, D. B. Tanner, W. S. Huang, and A. G. Macdiarmid, Phy. Rev. Lett. 59, 1446 (1987).

3. A. J. Heeger, S. Kivelson, J. R. Schrietter and W. P. Su, Rev Mod Phys. 60, 781 (1988).

4. Y. Cao, P. Smith and A. J. Heeger, Synth Met. 32, 263 (1989).

5. A. G. Macdiarmid and A. J.Epstein, J. Chem Soc Faraday Trans. 5, 1 (1989).

6. M. A. De Paoli, R. J. Waltman, A. F. Diaz and J. Bargon, J. Polym. Sci. Pol. Chem. 23, 1687 (1985).

7. O. Niwa and T. J. Tamamura, Chem. Soc. Chem. Commun, 817, (1984).

8. V.; Bocchi and G. P. Gardini, J. Chem. Soc. Chem. Commun, 148 (1986).

9. J. Roneali and G. P. Garini, J. Chem. Soc. Chem. Commun. 92, 833 (1988).

10. I. Sakurada, "Polyvinyl Alcohol” (Mercel Dekker, New York, 1985).

11. R. H. Baughman, et al., Chem. Rev. 82, 209 (1982).

12. D. Bloor and B. Movagher, IEE Proc. 130, 225 (1983).

13. M.A. Fahim, M. Roshdy and H. Osama, Proc. Math. Phys. Soc. Egypt, No. 64, 37 (1987)

14. H. VanSwygenhoven A. Caro, Nanostruct, Mater, 9, 669 (1997)

15. H. Van Swygenhoven and A. Caro, Nanostruct. Mater. 9, 669 (1997).

16. M. B. Heaney, Phys.Rev. B52, 12, 477 (1995).

17. M. Nelkon, "Mechanics and Properties of Matter", $5^{\text {th }}$ edition, Heinemann Educational Books; p. 124.

18. R. Kamel and K. H. Georgy, Mater. Sci. Eng. 33, 143 (1979). 